This work is licensed under a Creative Commons Attribution 4.0 International License https://creativecommons.org/licenses/by/4.0/

\title{
IMAGE AS A MODEL IN THE GERMAN LANGUAGE: PRACTICES OF DEFINITIONAL ANALYSES
}

\author{
Olga V. Printsipalova \\ Moscow State Institute of International Relations (University), \\ 76, Prospect Vernadskogo, Moscow, 119454, Russia.
}

\begin{abstract}
The paper considers the semantic structure of the concept IMAGE in the German language. The article presents the results of the definitional analysis of the lexeme "Image". The procedure of the definitional analysis, which enabled us to identify cognitive integral elements in order to objectify the concept of IMAGE, is specified. The classification of all identified semes is given in accordance with the activity-based approach; and the dominants of the ideal cognitive model of IMAGE are singled out, which include SUBJECT, OBJECT, MOTIVES, RESULTATIVE, and PROCEDURAL-SUBSTANTIVE SIDES of the concept. The structure of the idealized cognitive model of IMAGE is constructed of the units identified at the three stages of componential analysis. It is argued that the idealized conceptual model is associated with positive characteristics of an individual or a group of people in the eyes of others. At the same time the terminals included in the slots of the cognitive model are attacked in order to discredit a political opponent or to indicate the negative consequences of the politics conducted by the members of the outgroup. The author comes to the conclusion that the speaker purposefully tries to present his political opponents as inconsistent with the idealized cognitive model of IMAGE, discrediting their positive image in the eyes of others.
\end{abstract}

Key Words: image, ideal cognitive model, concept, componential analysis, language modeling

For citation: Printsipalova O.V. 2021. Image as a Model in the German Language: Practices of Definitional Analyses. Philological Sciences at MGIMO.Vol. 7. No 1(25). P. 83-90. https://doi. org/10.24833/2410-2423-2021-1-25-83-90

\section{МОДЕЛЬ ИМИДЖА В НЕМЕЦКОМ ЯЗЫКЕ: ОПЫТ ДЕФИНИЦИОННОГО АНАЛИЗА}

\section{О.В. Принципалова}

Московский государственный институт международных отношений МИД России, 119454, Россия, Москва, пр. Вернадского, 76 
Аннотация. В статье рассматривается семантическая структура понятия ИМИДЖ в немецком языке на основе результатов дефиниционного анализа лексемы „Iтаgе“. Уточняется процедура проведения дебиниционного анализа, при котором были выделены когнитивные интегральные элементы для объективации значения понятия ИМИДЖ. Приводится классификаиия всех выявленных сем в соответствии с деятельностным подходом и выделяются доминанты идеализированной когнитивной модели ИМИДЖ: СУБЪЕКТ, ОБЪЕКТ, МОТИВЫ, РЕЗУЛЬТИРУЮЩАЯ СТОРОНА, ПРОЦЕССУАЛЬНО-СОДЕРЖАТЕЛЬНАЯ СТОРОНА. Определяется структура идеализированной когнитивной модели ИМИДЖ, единиць которой были выявлены на трёх этапах дебиниционного анализа. Доказывается, что идеализированное представление связано с набором положительных характеристик отдельной тичности или группь людей в глазах окружающих, в то время как для уничижения оппонента используются нападки на терминалы, входящие в слоты когнитивной модели, с иелью дискредитации политического оппонента или указания на негативные последствия политики «чужих». Автор приходит к выводу, что оратор иеленаправленно пытается представить своих политических оппонентов как несоответствующих идеализированной когнитивной модели ИМИДЖ, дискредитируя их позитивный образ в глазах окружающцих.

Ключевые слова: имидж, идеализированная когнитивная модель, кониепт, дефиниционньй анализ, языковое моделирование

Для цитирования: Принципалова О.В. 2021. Модель имиджа в немецком языке: опыт дефиниционного анализа. Филологические науки в МГИМО. Том 7. № 1(25). С. 83-90. https://doi. org/10.24833/2410-2423-2021-1-25-83-90

\section{1. Введение}

$\mathrm{B}$ жизнедеятельности социума персонализация политики стала особенно актуальной. В борьбе за умы, внимание и голоса избирателей на передний план выходит имидж политических партий и их членов. Имидж политика представляет собой, с одной стороны, многоструктурное лингвокогнитивное образование, базирующееся на этнокультурной почве, с другой стороны, имидж политического лидера является социопсихологическим феноменом [10, с. 74]. Благосклонность избирателей получает тот политик, имидж которого вызвал их доверие и победил в межпартийной конкуренции.

Для того чтобы коммуникация протекала успешно, говорящий должен производить речевые действия, направленные на поддержание имиджа своих собеседников (англ. face work, нем. Imagearbeit). В исследованиях вербальной манифестации имиджа коммуникантов отмечается, что речевые усилия по поддержанию имиджа являются «не целью, а условием ... «протекания» и структурным признаком интеракции. Для хода успешной коммуникации от каждого её участника ожидается, что он не только будет требовать уважения к себе, но и сам будет тактичным к оппоненту. Другими словами, участники коммуникации должны кооперироваться, выстраивая свою интеракцию в соответствии с ритуальными правилами» [3, с. 78-79]. Если названные условия нарушаются, то собеседники начинают совершать нападки на позитивный имидж друг друга и интеракция перетекает в модус агрессивного речевого поведения.

Являясь носителем смыслов, информационным феноменом, ИМИДЖ предъявляет информацию в её соответствии нормам, принятым в рамках данного сообщества и в определённом общекультурном контексте [11, с. 93]. В связи с этим имидж партий призван вызывать набор ассоциаций, которые отражают предназначение партии в обществе и государстве в целом. Элементы, выражающие понятие ИМИДЖ, определяются при анализе структуры и модели формирования имиджа [5, с. 162]. Несмотря на разнообразие определений и интерпретаций ИМИДЖА, можно выделить общие характеристики при толковании этого понятия: имидж формируется целена- 
правленно, приобретает статус ментального стереотипа, оказывает эмоционально-психологическое воздействие [8, с. 81]. Очевидна связь сущности ИМИДЖА с идеями власти, чести и славы [1, с. 319].

Ранее уже предпринимались попытки описать понятийную составляющую концепта IMAGE, как, например, В.О. Радищевой в статье «Анализ понятийного компонента концепта «IMAGE» на материале немецкого языка» [9]. Однако, в указанной работе анализ проводился на уровне лексем, относящихся к ядру концепта. Цель же настоящего исследования - провести многоуровневый дефиниционный анализ немецкой лексемы „Image“ и выявить не только ядерные, но и периферийные семы, которые помогут определить доминанты и произвести языковое моделирование позитивного имиджа.

\section{2. Методика и материал исследования}

В настоящей статье для определения концептуального содержания понятия «имидж» мы провели его обширный дефиниционный анализ. Данный метод лингвистического исследования предлагает процедуру описания лексической семантики, создающей содержательное наполнение концепта. В нашем случае это концепт ИМИДЖ.

Дефиниционный анализ как метод лингвистического исследования является, по мнению М.В. Моисеева, продолжением и разновидностью компонентного анализа [7, с. 143]. При компонентном анализе слово раскладывается на его составляющие, так называемые семантические компоненты или семы. И.В. Арнольд отмечает, что семы представляют собой слагаемые лексического значения, отражающие признаки объектов, которые могут распознаваться данным языком [2, с. 52]. Лексические значения представлены в словарных дефинициях. При дефиниционном методе значение слова выявляется из его словарного толкования. Передача значения одного слова происходит при помощи других слов. При этом определяемое имеет меньше компонентов, чем определяющее, которое классифицирует семы в составе значения [2, с. 54]. Таким образом, значение слова представляет собой иерархическую единую систему, компоненты которой связаны между собой.

Дефиниционный анализ в немецкой генеративной и интерпретативной семантике обозначается термином Komponenten-, Merkamalanalyse (компонентный анализ, анализ признаков/характеристик). Тем самым подчёркивается, что данный метод основывается на том, что значение слова состоит из мельчайших когнитивных или понятийных элементов, семантических признаков, которые описываются при помощи универсальных категорий. То есть дефиниционный анализ позволяет выделить когнитивно-семантические элементы концепта и его лексических репрезентаций.

Традиционная реализация дефиниционного анализа состоит, главным образом, в обращении к словарным дефинициям лексем, участвующих в процессе номинации изучаемого концепта. Методом сплошной выборки устанавливается корпус лексических единиц, обладающих общим ключевым семантическим значением. Для этого вначале следует установить стержневые лексемы в тезаурусном ряду, вербализующие рассматриваемый концепт. Стержневые лексемы содержат в себе конститутивную сему, которая присутствует во всех остальных выявленных лексических единицах. Помимо прочего, словарные статьи в различных толковых и лексикографических словарях позволяют выявить дополнительные семы, которые помогают выстроить многомерную структуру концепта.

Анализ дефиниций представляет собой эффективный метод, адаптированный когнитивной лингвистикой из исследовательского инструментария семантики. Данный метод лингвистического анализа предлагает процедуру описания лексической семантики, создающей содержательное наполнение концепта. В нашем случае это концепт IMAGE.

Для более подробного отбора и детального рассмотрения компонентов концепта IMAGE, мы несколько модифицировали процедуру реализации метода дефиниционного анализа. На первом этапе был проведён компонентный анализ лексемы Image в авторитетных толковых немецкоязычных словарях: Duden. Das große Wörterbuch der deutschen Sprache [14], Wahrig G. 
Deutsches Wörterbuch [18], Langenscheidt Großwörterbuch Deutsch als Fremdsprache [16], PONS Großwörterbuch Deutsch als Fremdsprache [17], DWDS. Digitales Wörterbuch der deutschen Sprache [13], и выявлены все его семы.

На втором этапе реализации дефиниционного анализа для каждой лексической единицы из установленного синонимического ряда, в свою очередь, выявлялись новые синонимы.

На третьем этапе проведения дефиниционного анализа все выявленные лексемы были подвергнуты компонентному семантическому анализу с помощью вышеназванных толковых словарей немецкого языка.

Как и любой акт речевого поведения, вербальные действия говорящего, направленные на поддержание своего имиджа или ущемление имиджа оппонентов, можно представить в виде определённой концептуальной модели с помощью фреймо-слотовой структуры [ср. напр.: 4, с. 35]. В связи с идеализацией образа политиков и возможной его трансформацией в глазах избирателей целесообразно обратиться к идеализированным когнитивным моделям (ИКМ), с помощью которых структурируется понятийная система человека. Теория ИКМ впервые была описана Дж. Лакоффом, который характеризует их как один из типов когнитивных структур [15], наиболее значимыми из которых являются следующие модели: пропозициональные ИКМ, образно-схематические ИКМ, метафорические ИКМ, метонимические ИКМ. ИКМ вычленяют элементы, дают им характеристики и указывают на связи между ними. Основой для построения ИКМ служат среди прочего: 1) социальные стереотипы; 2) типичные примеры; 3) идеалы; 4) лучшие и худшие образцы [6, с. 61-66].

\section{3. ИКМ ИМИДЖ и её составляющие}

Трёхэтапный дефиниционный анализ позволил выявить в общей сложности 45 единиц, ассоциируемых с понятием IMAGE. Словарные статьи лексемы „Image“ в авторитетных толковых словарях немецкого языка показал, что IMAGE связан с такими положительными проявлениями отдельной личности или группы людей в глазах окружающих, как престиж/достоинство (Ansehen), образ (Bild), слава (Leumund), репутация (Ruf, Reputation); ореол (Nimbus), престиж (Prestige), характерные черты (Profil), реноме (Renommee).

Далее для каждой лексической единицы из установленного синонимического ряда были выявлены новые синонимы. На следующем этапе дефиниционного анализа были выбраны лексемы, у которых хотя бы одна сема коррелирует с семами слова Image. К таким словам относятся Autorität, Corporate Identity, Format, Geruch, Name, Nimbus, Rang, Respekt, Rückgrat, Status, Stellung, Ruhm.

Дефиниционный анализ концепта IMAGE позволяет установить концептуальные связи между составляющими компонентами всей структуры вышеназванного концепта. Так, лексема Bild (образ) является одним из составляющих концепта IMAGE и расширяет своё концептуальное значение с помощью синонима Vorstellung (представление).

Имидж политика формируется не только его политическими позициями, которые он отстаивает. Язык, риторика, жесты, способы общения с другими политическими деятелями и гражданами, а также образ жизни, семья и хобби оставляют определённый отпечаток, обозначаемый в Duden посредством лексемы Eindruck (впечатление).

Лексема Autorität (авторитет) приводится в словарях в сочетаемости с прилагательными moralisch, staatlich, что подчёркивает значимость социальной функции личности. Общепризнанную весомость человека, который благодаря своим знаниям выносит суждения, признающиеся широкими слоями населения и вызывающие доверие, обнаруживаем также в лексеме Geltung (значимость, ценность), представленной в Wahrig. Понятие Autorität часто коррелирует со словами Macht (власть) и Einfluss (влияние), что указывает на наделение правом человека во власти воздействовать на жизнедеятельность членов общества.

Схожим значением обладает лексема Ansehen (престиж/достоинство). Все использованные нами словари трактуют это понятие как Achtung (уважение) и gute/hohe Meinung (хорошее/высокое мнение). В словаре Wahrig дополнительно представлено значение Würde (достоинство). 
В толковом словаре Duden для объяснения понятия Ansehen вводится лексема Anerkennung (признание). Признание заслуг имеет следствием утверждение и уважение политика или его партии в общественном сознании.

Помимо прочего, Duden предлагает для дефиниции понятия Ansehen дополнительный признак - лексему Wertschätzung (уважение/оценка значимости), которая существенно расширяет концепт IMAGE.

Понятие Respekt детализируется с помощью синонимичных лексем Bewunderung (восхищение), Ehrerbietung (почитание), Ehrfurcht (глубокое уважение), из чего становится очевидным, что восхищение и уважение окружающих, которое вызвано правильными и профессиональными действиями политика, являются важными составляющими компонентами концепта IMAGE.

Одним из ключевых составляющих элементов концепта IMAGE является Renommee (реноме) репутация уважаемого лица. Положительное реноме в глазах избирателей становится главным фактором, который обеспечивает высокую степень доверия. Для политика важен результат, поэтому на реноме отражаются такие факторы как профессионализм, умение держать слово, стремление улучшать жизнь народа.

Престиж политика или его партии выражает меру социального статуса, общественное признание авторитетов. Престиж часто отождествляется с уважением и статусом. Лексема Status (статус) в словаре Wahrig рассматривается в связи с положением внутри определённой общественной группы (gesellschaftliche Stellung). Люди, обладающие одинаковым престижем, то есть пользующиеся одинаковой степенью признания, образуют единую статусную группу. Статус наделяет своих владельцев определёнными обязанностями и правами, возможностями и влиянием.

Дефиниция понятия Stellung (позиция, точка зрения) связана со степенью значимости и признания внутри определённой иерархии. В качестве синонимов словари немецкого языка приводят Rang, Position. Сочетания von hohem Rang и ersten Ranges указывают на значимость и весомость в обществе индивида. Характеристика «высший разряд/высшая категория» свидетельствует о высокой степени профессионализма и надежности.

Особо высокая степень доверия, достоинства и уважения включена в понятие Nimbus (ореол). Эффект ореола в общественном сознании усиливается характеристикой glanzvoller Ruhm (блистательная слава). Пытаясь понять происходящее вокруг, избиратель даёт свою интерпретацию действиям и процессам. Политик наделяется вымышленными качествами, благодаря которым происходит типологизация его деятельности. Процессы атрибуции (приписывания) служат основой для создания ореола. Положительный ореол в одной сфере проецируется на безусловный успех в другой.

Одним из самых частотных компонентов обозначенного концепта IMAGE выступает слово Ruf, Reputation (репутация). В создании и поддержании имиджа политика немаловажную роль играет его репутация, а лексемы для их выражения Ruf и Reputation некоторыми исследователями рассматриваются как синонимы, так как обе лексемы отображают процессы восприятия и оценки избирателей. Репутация (от лат. reputatio - обдумывание, созерцание) связана с социальной предсказуемостью, другими словами, с определёнными ожиданиями социума, которые он выдвигает к личности, объекту или продукту в целом [12;14].

Дополнительным элементом к уже имеющимся Leumund, Ansehen (молва, слава, признание) является сочетание Urteil der Allgemeinheit (суждение, мнение общественности) в словарях Langenscheidt и Duden. Репутация выражает коллективное мнение окружающих, то есть восприятие субъекта через призму общественного мнения, а также через его стереотипизацию. Иными словами, полученные впечатления об объекте восприятия обобщаются на основании сходства с прежними впечатлениями. В сочетании с такими признаками, как gut, schlecht, zweifelhaft, groß, übel лексемы „Ruf/Reputation“ выражают оценочное суждение о качествах личности или группы лиц. Репутация как одна из составляющих имиджа представляет собой устойчивую смысловую конструкцию, которая формируется на внутреннем уровне в зависимости от конъюнктурных потребностей электората. 
Лексема Name, употребляемая в значении «репутация/известность», представляет собой ещё одно звено в компонентном анализе понятия IMAGE. Делая себе имя, то есть создавая репутацию, политик должен совершать свои политические действии в соответствии с общепринятыми ценностями. Обещания, гарантии их выполнения и результат выполненных обещаний создают положительное имя, позволяют заработать авторитет в глазах избирателей и тем самым повысить свой рейтинг.

Важность репутации для создания имиджа прослеживается в дефиниции понятия Corporate Identity, где корпоративная репутация организации, её презентация (Erscheinungsbild - (внешний вид)) в обществе выступает как стратегический концепт философии этой компании, направленный на создание положительного долгосрочного впечатления. Политическая идентичность похожа на корпоративную идентичность тем, что выражается в принадлежности к определённой группе, в данном случае к политической партии, и в проявлении себя в соответствии с ценностями данной группы. Деловая, как и личная, репутация очень уязвима и должна постоянно поддерживаться на высоком уровне через разного рода деятельность, результаты которой соответствуют общепринятым ценностям.

Кроме деловой репутации важную роль играет Selbstdarstellung (самодемонстрация/самопрезентация; поведение, рассчитанное на эффект). Самопрезентация осуществляется самим носителем имиджа. Построение имиджа относится к прагматическим стратегиям, то есть к стратегиям, которые направлены на достижение заданного результата, а именно на получение голосов избирателей. Самопрезентация политика направлена на то, чтобы показать свою принадлежность к электорату, и что он является частью этого электората.

Ещё один дополнительный признак концепта IMAGE выражается лексемой Format (формат), которая связана с такой характеристикой лица, как значимость его положения. Словарь PONS выделяет в понятии формата «большое значение человека как личности» (jds große Bedeutung als Persönlichkeit), а в словаре Duden в определении формата присутствует признак «незаурядный, исключительный» (außergewöhnlicher Rang, ausgeprägtes Persönlichkeitsbild). В политическом дискурсе внимание аудитории в первую очередь фокусируется на индивидуальности политического деятеля, на его особенных способностях, оценивается его поведение по критериям социальных стандартов. Таким образом, формат создаёт у электората нужное эмоциональное восприятие политического деятеля или партии.

В реализации концепта IMAGE принимает участие также лексема Profil. Словари PONS и Duden определяют Profil как „Gesamtheit stark ausgeprägte kennzeichnende Eigenschaften, die als Gesamtheit, einer Person oder Sache ihren besonderen Wert geben / die unverwechselbar typisch für jmdn. oder etw. sind“. Из этого следует, что совокупность характеристик, которые многоаспектно описывают деятельность и компетенции политического актора, способствуют его политической идентификации.

Лексема Rückgrat (характер, стойкость, твёрдость) в корреляции с концептом IMAGE, а также её синонимы Charakter (характер) и Zivilcourage (гражданское мужество) представляют характеристики идеального политика. Желание политика вмешиваться в критические ситуации с целью их решения, умение проявить стойкость и твёрдость характера при отстаивании своей позиции вызывает уважение и доверие граждан.

Смысловое наполнение концепта IMAGE усиливается лексемой Leumund (слава). В словарях Duden и DWDS в дефиниции понятия Leumund обнаруживается характеристика Nachrede (молва, дурная слава), которая может быть отнесена к периферии концепта. Негативные слухи, молва часто связаны с недостоверностью и ложностью информации. Хорошая или дурная слава выступает в соответствующей роли катализатора политических настроений.

Тезаурусный ряд понятия «репутация» дополняется несколькими лексемами с отрицательной коннотацией - Verruf (дурная слава) и Geruch (дурная репутация/дурная слава). Дурная слава личности создаётся в глазах общественности на основе невыполнения этим человеком обязательств или нарушения моральных принципов. Это - общественная оценка недостатков политика. Непривлекательный образ политика и/или партии способствует ослаблению доверия и дискредитации престижа. Расширяя данную дефиницию, в словарях появляется характеристика allgemeine, meist schlechte Meinung (общественное, как правило, плохое мнение). 
Информация, воспринимаемая сначала индивидом, а затем и обществом, после процесса обработки в результате находит своё отражение в мнениях и суждениях об объекте, в нашем случае о политическом деятеле или его партии. Сложившийся имидж позволяет избирателям просчитать, как политик поведёт себя в будущем. Такая предсказуемость облегчает и упрощает процесс принятия решения избирателем на основе ряда отличительных признаков, например: надёжность, верность слову, ответственность и т.д. - Glaubwürdigkeit (надёжность, доверительность), Unbescholtenheit (незапятнанность).

\section{4. Выводы}

Трёхэтапный дефиниционный анализа немецкой лексемы „Image“ на основе 5 толковых словарей немецкого языка позволил выявить в общей сложности 45 единиц, включая её синонимы и другие лексемы, семы которых ассоциируются с субстанциальными характеристиками концепта IMAGE. Все компоненты концепта IMAGE образуют идеализированную когнитивную модель ИМИДЖ. Основой для структурирования всех выявленных сем немецкой лексемы „Image“ в рамках идеализированной когнитивной модели ИМИДЖ может служить деятельностный подход. Согласно этому подходу, любая активность человека, в том числе и исследуемые нами вербальные усилия по поддержанию своего имиджа или нанесению урона имиджу оппонента, имеют следующую структуру: 1) СУБЪЕКТ ИМИДЖА (Кто?), 2) ОБЪЕКТ ИМИДЖА (Для кого?), 3) МОТИВАЦИОННАЯ СТОРОНА ИМИДЖА (Зачем?), 4) РЕЗУЛЬТИРУЮЩАЯ НАПРАВЛЕННОСТЬ ИМИДЖА (Какой результат достигнут или не достигнут?), 5) ПРОЦЕССУАЛЬНО-СОДЕРЖАТЕЛЬНАЯ СТОРОНА ИМИДЖА (Как действует субъект имиджа?). Эти элементы выступают в качестве доминант идеализированной когнитивной модели ИМИДЖ. Каждая доминанта находит свою вербальную манифестацию в виде набора слотов в условиях реального речевого взаимодействия коммуникантов.

(C) Принципалова О.В., 2021

\section{Список литературы}

1. Абдиева Г.М. Концепт «ИМИДЖ» в современной лингвокультуре / Г.М. Абдиева, Д. Шайбакова. Мир науки, культуры, образования. 2020. №1 (80). С. 317-320.

2. Арнольд И. В. Основы научных исследований в лингвистике: Учеб. Пособие. М.: Высшая школа, 1991. 140 с.

3. Глушак В.М. Имидженарушающее поведение в высокоэмоциональной интеракции // Вестник Московского государственного лингвистического университета. 2009. № 560. С. 78-87.

4. лушак В.М. Языковое моделирование образцов речевого поведения // Вестник Тамбовского университета. Серия: Гуманитарные науки. 2007. №7 (51). С. 35-42.

5. Депелян Р.А. Имидж политических партий // Социально-экономические науки и гуманитарные исследования. 2016. № 10. C. 161-165.

6. Лакофф Дж. Метафоры, которыми мы живём / пер. с англ.; под ред. и с предисл. А. Н. Баранова / Дж. Лакофф, М. Джонсон. М.: Едиториал УРСС, 2004. 256 с.

7. Моисеев М.В. Применение дефиниционного анализа в лингвокультурологическом исследовании // Вестник Омского государственного университета. Омск: Изд-во ОмГУ. 2010. № 3. С. 142-148.

8. Никитина Л. Б. Семантический потенциал термина «ИМИДЖ» в современном русском языке / Л. Б. Никитина, Е.В. Гейко. Вестник Омского государственного педагогического университета. Гуманитарные исследования. 2019. №4 (25). С. 80-84.

9. Радищева B.О. Анализ понятийного концепта «IMAGE» на материале немецкого языка // Филологические науки. Вопросы теории и практики. 2017. №7-3 (73). С. 169-171

10. Тамерьян Т. Ю. Имиджевая структура концепта KANZLERIN ANGELA MERKEL по данным немецких СмИ / Т. Ю. Тамерьян, В. А. Цаголова. Политическая лингвистика. 2018. №3. С. 69-75.

11. Цветкова Е.А. Культурологическая концепция имиджа // Вестник НГТУ им. Р.Е. Алексеева. Серия «Управление в социальных системах. Коммуникативные технологии». 2016. №. 1. С. 91-97.

12. Burkhardt R. Reputation Management in Small and Medium-sized Enterprises. Analysis and evaluation of the use of Reputation Management: A survey of Small and Medium-sized Enterprises in Germany. Hamburg: Diplomica Verlag, 2008. 122 S.

13. DWDS. Digitales Wörterbuch der deutschen Sprache [Электронный ресурс]. - URL: https://www.dwds.de/ (дата доступа 12.08.2020) 
14. Duden. Das große Wörterbuch der deutschen Sprache [Электронный pecypc]. - URL: https://www.duden.de/woerterbuch (дата доступа 09.08.2020)

15. Lakoff G. Women, fire, and dangerous things: What categories reveal about the mind. Chicago: University of Chicago Press, $1990.614 \mathrm{p}$.

16. Langenscheidt Großwörterbuch Deutsch als Fremdsprache. Berlin, München, Wien, Zürich, New York: Langenscheidt, 2010. $1513 \mathrm{~S}$.

17. PONS Großwörterbuch Deutsch als Fremdsprache: Das neue Wörterbuch für Alltag, Unterricht, Studium und Beruf. Stuttgart: Ernst Klett Sprachen, 2004. 1700 S.

18. Wahrig G. Deutsches Wörterbuch. Mit einem «Lexikon der deutschen Sprachlehre». Gütersloh, München: Bertelsmann Lexikon Institut, 2006. 1728 S.

\section{References}

1. Abdieva, G.M., Shaibakova D. Kontsept «IMIDZh» v sovremennoi lingvokul'ture [The concept "IMAGE" in the modern linguoculture] // Mir nauki, kul'tury, obrazovaniia. 2020. №1 (80). pp. 317-320.

2. Arnol'd, I. V. Osnovy nauchnykh issledovanii v lingvistike [Fundamentals of Scientific Research in Linguistics]: Ucheb. posobie - M.: Vysshaia shkola, 1991. 140 p.

3. Glushak, V.M. Imidzhenarushaiushchee povedenie v vysokoemotsional'noi interaktsii [Image-disturbing behavior in highly emotional interaction] // Vestnik Moskovskogo gosudarstvennogo lingvisticheskogo universiteta. 2009. № 560. pp. 78-87.

4. Glushak, V.M. Iazykovoe modelirovanie obraztsov rechevogo povedeniia [Language modeling of patterns of speech behavior] // Vestnik Tambovskogo universiteta. Seriia: Gumanitarnye nauki. 2007. №7 (51). pp. 35-42.

5. Depelian, R.A. Imidzh politicheskikh partii [Image of political parties] // Sotsialno-ekonomicheskie nauki i gumanitarnye issledovaniia. 2016. № 10. pp. 161-165.

6. Lakoff, Dzh., Dzhonson, M. Metafory, kotorymi my zhivem [Metaphors we live by]/ per. s angl.; pod red. I s predisl. A. N. Baranova. M.: Editorial URSS, 2004. 256 p.

7. Moiseev, M. V. Primenenie definitsionnogo analiza v lingvokul'turologicheskom issledovanii [Definitional analysis in cultural linguistic research] // Vestnik Omskogo gosudarstvennogo universiteta. Omsk: Izd-vo OmGU. 2010. № 3. pp. 142-148.

8. Nikitina, L. B., Geiko, E. V. Semanticheskii potentsial termina «IMIDZh» v sovremennom russkom iazyke // Vestnik Omskogo gosudarstvennogo pedagogicheskogo universiteta. Gumanitarnye issledovaniia. 2019. №4 (25). pp. 80-84.

9. Radishcheva, V.O. Analiz poniatiinogo kontsepta «IMAGE» na materiale nemetskogo iazyka [Analyses of the notional component of the concept "IMAGE" on the material of the German language] // Filologicheskie nauki. Voprosy teorii i praktiki. 2017. №7-3 (73). pp. 169-171.

10. Tamer'ian, T. Iu., Tsagolova, V.A. Imidzhevaia struktura kontsepta KANZLERIN ANGELA MERKEL po dannym nemetskikh SMI [The IMAGE structure of the concept chancellor Angela Merkel based on the German media] // Politicheskaia lingvistika. 2018. №3. pp. 69-75.

11. Tsvetkova, E.A. Kul'turologicheskaia kontseptsiia imidzha [Cultural concept of IMAGE] // Vestnik NGTU im. R.E. Alekseeva. Seriia «Upravlenie v sotsial'nykh sistemakh. Kommunikativnye tekhnologii». 2016. №. 1. pp. 91-97.

12. Burkhardt, R. Reputation Management in Small and Medium-sized Enterprises. Analysis and evaluation of the use of Reputation Management: A survey of Small and Medium-sized Enterprises in Germany. Hamburg: Diplomica Verlag, 2008. $122 \mathrm{p}$.

13. DWDS. Digitales Wörterbuch der deutschen Sprache, www.dwds.de/ (accessed 12.08.2020)

14. Duden. Das große Wörterbuch der deutschen Sprache, www.duden.de/woerterbuch (accessed 09.08.2020)

15. Lakoff, G. Women, fire, and dangerous things: What categories reveal about the mind. Chicago: University of Chicago Press, $1990.614 \mathrm{p}$.

16. Langenscheidt Großwörterbuch Deutsch als Fremdsprache. Berlin, München, Wien, Zürich, New York: Langenscheidt, 2010. $1513 \mathrm{p}$.

17. PONS Großwörterbuch Deutsch als Fremdsprache: Das neue Wörterbuch für Alltag, Unterricht, Studium und Beruf. Stuttgart: Ernst Klett Sprachen, 2004. 1700 p.

18. Wahrig, G. Deutsches Wörterbuch. Mit einem «Lexikon der deutschen Sprachlehre». Gütersloh, München: Bertelsmann Lexikon Institut, 2006. $1728 \mathrm{p}$.

\section{Сведения об авторе:}

Принципалова Ольга Вячеславовна - старший преподаватель кафедры немецкого языка МГИМО МИД России (Москва, Россия). Сфера научных и профессиональных интересов: политическая и когнитивная лингвистика. E-mail: o.printsipalova@my.mgimo.ru

\section{About the author:}

Olga V. Printsipalova - a Senior Teacher, Department of the German Language, MGIMO University (Moscow, Russia). Spheres of research and professional interest: political and cognitive linguistics.

E-mail: o.printsipalova@my.mgimo.ru 